\title{
Topical Calcineurin Inhibitors for Atopic Dermatitis: Review and Treatment Recommendations
}

\author{
Warner W. Carr
}

Published online: 3 April 2013

(c) The Author(s) 2013. This article is published with open access at Springerlink.com

\begin{abstract}
Atopic dermatitis (AD) is an inflammatory skin disease commonly affecting children and managed by pediatricians, primary care physicians, allergists, and dermatologists alike. For many years, the only available topical pharmacological treatment was topical corticosteroids. This changed in 2000-2001, when topical formulations of two calcineurin inhibitors (tacrolimus and pimecrolimus) were approved for short-term or chronic intermittent treatment of $\mathrm{AD}$ in patients $\geq 2$ years of age, in whom other treatments have been ineffective or contraindicated. These topical calcineurin inhibitors (TCIs) quickly became a popular treatment option due at least in part to concerns over adverse events associated with prolonged topical corticosteroid use, especially in children. However, based on theoretical concerns about a possible risk of lymphoma associated with TCI use, a Boxed Warning was placed on both products in 2006. Since then, despite an extensive body of evidence, no causal relationship has been demonstrated between TCI use and an increased risk of lymphoma; however, the US FDA has concluded that a link cannot be ruled out. In fact, based on post-marketing surveillance of spontaneous, literature, and solicited reports, we report here that the lymphoma incidence in the topical pimecrolimus-exposed population is up to approximately 54-fold less than that seen in the general US population. This review summarizes the mechanism of action of TCIs, the factors that prompted the Boxed Warning, and recent TCI safety and efficacy data. Based on these data, both topical corticosteroids and TCIs should have defined roles in AD management, with TCIs favored for sensitive skin areas (e.g., face) and instances where topical
\end{abstract}

\section{W. W. Carr $(\bowtie)$}

Allergy and Asthma Associates of Southern California, Southern California Research, 27800 Medical Center Road, Suite 244, Mission Viejo, CA 92691, USA

e-mail: wcarr@allergee.com corticosteroids have proven ineffective, thereby minimizing the risk of adverse effects with both drug classes.

\section{Introduction}

Atopic dermatitis (AD) is an inflammatory skin disease that predominantly affects children, with approximately $70 \%$ of first diagnoses made in children $<5$ years of age [1]. According to a US PharMetrics study, most AD sufferers are treated by pediatricians $(\sim 30 \%)$, dermatologists $(\sim 25 \%)$, or primary care physicians $(\sim 20 \%)$ [2]. Topical corticosteroids have long been and remain the mainstay of $\mathrm{AD}$ flare treatment; however, their use is limited by concerns about local and systemic adverse effects with extended use [3, 4]. After their approval in 2000-2001, topical calcineurin inhibitors (TCIs; tacrolimus 0.03 or $0.1 \%$ and pimecrolimus $1 \%)$ quickly became popular alternatives to topical corticosteroids; however, since 2006, TCI use has fallen dramatically after the addition of a Boxed Warning to each product's label about a theoretical risk of malignancy (including lymphoma). Since that time, significant new epidemiologic and clinical data have become available that challenge the validity of this warning. This article provides an update on these data, summarizes the mechanism of action of TCIs, discusses the factors that prompted the classwide warning, and provides guidance for the optimal use of TCIs from an allergist's perspective.

\section{Atopic Dermatitis: Overview}

\subsection{Clinical Manifestations and Prevalence}

Major clinical manifestations of $\mathrm{AD}$ include pruritus (itching) and chronic or relapsing scaly lesions. Diagnostic 
criteria include evidence of itchy skin and $\geq 3$ of the following: history of involvement of skin creases [fronts of elbows or ankles, backs of knees, or around the neck (including cheeks in children $<10$ years of age)], history of asthma or hay fever (or, in children $<4$ years of age, a history of atopic disease in a first-degree relative), history of generally dry skin in the past year, onset before the age of 2 years (in children $\geq 4$ years of age), or visible flexural dermatitis (including the cheeks or forehead and outer aspects of limbs in children $<4$ years of age) [5].

Results of the International Study of Asthma and Allergies in Childhood (ISAAC) demonstrated great variability in the worldwide prevalence of $\mathrm{AD}$ with ranges of $0.2-24.6 \%$ for patients $13-14$ years of age $(n=663,256)$ and $0.9-22.5 \%$ for patients $6-7$ years of age $(n=$ 385,853 ) [6]. In the US, AD is estimated to affect $10.7 \%$ (7.9 million) of children, and the wide range in prevalence between regions (8.7-18.1\%) suggests that social and/or environmental factors may play a role in disease expression [7].

\subsection{Natural History and Mechanism}

The etiology of AD is very complex and not fully understood. It is believed that $\mathrm{AD}$ is a result of interactions between susceptibility genes and environmental factors [8]. Briefly, a genetic propensity toward a compromised epidermal barrier (including gene mutations for epidermal structural proteins such as filaggrin) increases the chances of penetration by allergens (Fig. 1) [9]. The process of sensitization is initiated when antigen-presenting cells, such as Langerhans' cells, process the antigen and present its fragments to lymphocytes, thereby stimulating the infiltration of helper $\mathrm{T}(\mathrm{Th})$ lymphocytes in the skin and polarizing Th0 lymphocyte differentiation toward the Th2 subtype. These Th2 lymphocytes secrete proinflammatory cytokines, including interleukin (IL)-3, IL-4, IL-5, and IL13 , and stimulate humoral immune responses (acute phase) [9]. The subsequent, chronic phase is characterized by a shift in Th lymphocyte differentiation toward the Th1 subtype, which in turn leads to secretion of a different set of proinflammatory cytokines (including interferon $\gamma$, IL12, IL-11, IL-18, granulocyte-macrophage colony-stimulating factor, and tumor growth factor $\beta$ ), as well as activation of cellular immune responses [9]. In addition, inflamed, excoriated skin has a greater potential for colonization by microorganisms such as Staphylococcus aureus, which produce antigens that can further stimulate sensitization [9].

\section{Treatment Approaches}

3.1 Emollients, Topical Corticosteroids, and the Emergence of Topical Calcineurin Inhibitors (TCIs)

There is currently no cure for $\mathrm{AD}$, so disease management is focused on trigger avoidance and alleviation of symptoms. First-line maintenance therapy includes nonpharmacological

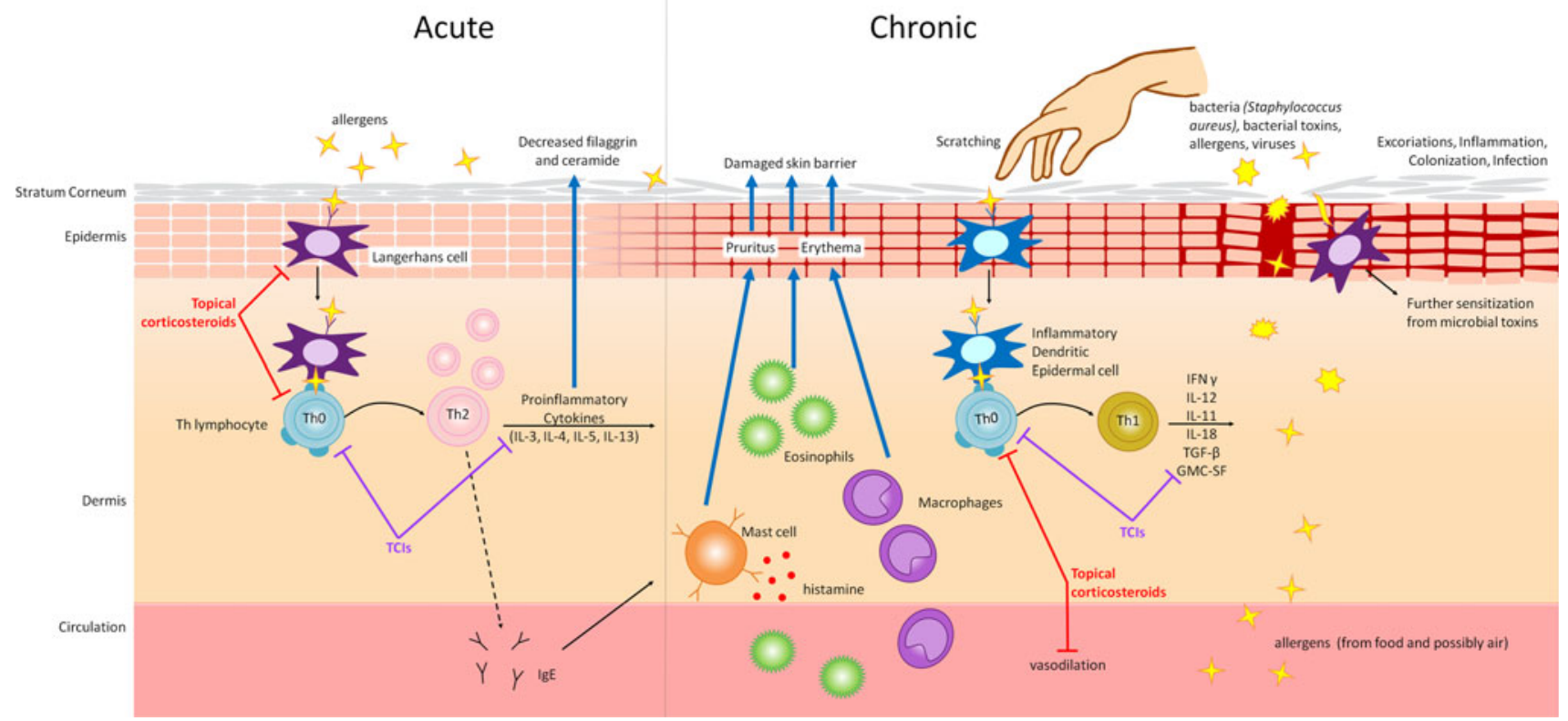

Fig. 1 The mechanism of atopic dermatitis and sites of action of topical calcineurin inhibitors and topical corticosteroids. GMC-SF granulocyte-macrophage colony-stimulating factor, $I F N \gamma$ interferon $\gamma$,
$I L$ interleukin, $I g E$ immunoglobulin E, TCI topical calcineurin inhibitor, $T G F-\beta$ tumor growth factor- $\beta$, Th helper T lymphocyte 
treatment with various emollients and skin barrier repair agents, which have been shown to improve skin appearance and dryness and/or to reduce the need for pharmacological treatment $[1,9]$. When flares occur, anti-inflammatory agents are used to control the inflammatory aspects of the disease. For many years, the main pharmacological option was topical corticosteroids; however, in December 2000, tacrolimus ointment $0.03 \%$ (for patients $\geq 2$ years of age) and $0.1 \%$ (for patients $>15$ years of age) were approved as second-line short-term or intermittent chronic therapy for patients $\geq 2$ years of age with moderate-to-severe AD [10]. In December 2001, pimecrolimus cream $1 \%$ was approved for the same indication in patients $\geq 2$ years of age with mild-tomoderate AD [11]. Due in part to concerns about corticosteroid use, TCIs quickly became a popular treatment option. Prior to the approval of tacrolimus (1997-2000), topical corticosteroids were prescribed during $34 \%$ of all AD-related visits in the US; between 2001 and 2004, that percentage fell to $25 \%$, and TCIs were prescribed during $23 \%$ of visits [12].

\subsection{TCIs: Mechanism of Action}

Tacrolimus and pimecrolimus are macrolactams with immunosuppressive characteristics. Both TCIs are thought to exert their immunosuppressive effects by inhibiting the activation of $\mathrm{T}$ lymphocytes, thereby decreasing the release of the various proinflammatory cytokines discussed previously (Fig. 1) [13]. Unlike topical corticosteroids, TCIs do not have an effect on Langerhans' cells and do not reduce the numbers of Th cells in healthy skin [13]. Transepidermal penetration of both TCIs is lower (70- to 100-fold) than that of topical corticosteroids, with the transepidermal flux of pimecrolimus in cream being approximately fivefold lower than the flux of tacrolimus in ointment [13]. Due to these characteristics, tacrolimus and pimecrolimus have been investigated for a number of other inflammatory skin diseases [14] and oral and intravenous tacrolimus is indicated for graft-versus-host prophylaxis [15].

\subsection{TCIs: Safety and Efficacy Comparisons with Topical Corticosteroids}

The emergence of tacrolimus and pimecrolimus offered a welcome alternative to topical corticosteroids, since the chronic use of topical corticosteroids has been associated with numerous adverse effects, ranging from local (skin atrophy, rebound dermatitis, telangiectasia, striae, and dyspigmentation) to systemic (hypothalamic-pituitaryadrenal axis suppression, growth retardation, and Cushing's syndrome) [4]. The risk of specific adverse effects depends on duration of use, corticosteroid potency, patient age, and application site, making the rates of these adverse events difficult to estimate [4]. It is due at least in part to the risk of these adverse events that efficacy and safety data for topical corticosteroids are limited. Based on the available data in adults, TCIs appear to be as effective or more effective than mild topical corticosteroids in controlling $\mathrm{AD}$, and equally or slightly less effective than potent topical corticosteroids [16-21] (Table 1). Skin burning (the most frequently reported adverse effect associated with TCI use) is more often reported with TCIs than topical corticosteroids (Table 1); however, it typically improves with the resolution of active AD lesions [22, 23].

\section{Boxed Warning for the TCIs}

\subsection{Rationale}

As with many drugs, the long-term safety of TCIs had not been fully established at the time of approval, and animal studies suggested the possibility of immune system-mediated malignancy (particularly lymphomas) with systemic exposure [24]. Furthermore, oral and intravenous tacrolimus administered for systemic immune suppression in transplant recipients is associated with an increased risk of immune-mediated malignancies, including lymphomas [15]. Consequently, at approval, the FDA required longterm pediatric safety registries for both agents [25, 26].

In early 2005, the FDA's Pediatric Advisory Committee (PAC) raised concerns about the widespread use of TCIs, particularly off-label prescriptions to infants, which by January 2004 had reached approximately 525,000 (14\% of yearly prescriptions) for pimecrolimus and 69,000 (7\%) for tacrolimus [27], and heavy direct-to-consumer advertising. Based on this, the animal data (mentioned above), and malignancy reports in the FDA's adverse event reporting system (AERS; 25 malignancies, 13 lymphomas in $>6.7$ million potential patients), the committee recommended that a Boxed Warning be added to both products [28]. However, because the incidence of malignancy had been low in clinical studies of either TCI $(>38,000$ patients, including $>14,000$ children), they concluded that a causal link had not been established, but was possible and plausible.

On January 16, 2006, the FDA accepted the PAC's recommendations and required that the prescribing information for tacrolimus and pimecrolimus be amended with a Boxed Warning. The warning states that, although a causal relationship had not been established, "rare cases of malignancies (e.g., skin cancer, melanoma) have been reported in patients treated with topical calcineurin inhibitors [22, 23]". This ultimately resulted in a $79 \%$ decrease in TCI prescriptions [27], loss of preferred status in many formularies, and sparked a benefit-risk debate that remains unresolved. 
Table 1 Comparative efficacy and tolerability between topical calcineurin inhibitors and topical corticosteroids ${ }^{\mathrm{a}}$

\begin{tabular}{|c|c|c|c|c|c|c|c|c|c|}
\hline \multirow[t]{3}{*}{ Methodology } & \multirow[t]{3}{*}{ Tolerability results } & \multicolumn{8}{|c|}{ Efficacy results } \\
\hline & & \multicolumn{4}{|c|}{ Tacrolimus vs. } & \multicolumn{4}{|c|}{ Pimecrolimus vs. } \\
\hline & & Vehicle & $\begin{array}{l}\text { Mild } \\
\text { CS }\end{array}$ & $\begin{array}{l}\text { Mid- } \\
\text { CS }\end{array}$ & $\begin{array}{l}\text { Potent } \\
\text { CS }\end{array}$ & Vehicle & $\begin{array}{l}\text { Mild } \\
\text { CS }\end{array}$ & $\begin{array}{l}\text { Mid- } \\
\text { CS }\end{array}$ & $\begin{array}{l}\text { Potent } \\
\text { CS }\end{array}$ \\
\hline $\begin{array}{l}\text { Meta-analysis of studies comparing } \\
\text { tacrolimus and pimecrolimus with } \\
\text { each other, topical corticosteroids, or } \\
\text { vehicle in patients with AD of any age } \\
(n=5,301)[16]\end{array}$ & - Both TCIs are well tolerated & $>$ & & $>$ & & $>$ & & $<$ & \\
\hline $\begin{array}{l}\text { Meta-analysis of randomized trials of } \\
\text { TCIs compared with topical } \\
\text { corticosteroids or vehicle in patients } \\
\text { of any age with AD }(n=6,687)[17]\end{array}$ & $\begin{array}{l}\text { - Skin burning is more } \\
\text { frequent with both TCIs than } \\
\text { topical corticosteroids } \\
\text { - Neither TCI is associated } \\
\text { with risk of skin infection } \\
\text { compared with vehicle or } \\
\text { topical corticosteroids }\end{array}$ & $>$ & $>$ & & $=$ & $>$ & $\mathrm{b}$ & & $<$ \\
\hline $\begin{array}{l}\text { Meta-analysis of randomized controlled } \\
\text { trials comparing tacrolimus with } \\
\text { pimecrolimus, topical corticosteroids, } \\
\text { or vehicle in children with AD } \\
(n=712 \text { tacrolimus-treated })[18]\end{array}$ & $\begin{array}{l}\text { - Tacrolimus is similar in } \\
\text { tolerability to vehicle and } \\
\text { pimecrolimus, but greater in } \\
\text { tolerability than } 1 \% \mathrm{HCT} \\
\text { - Burning and pruritus are } \\
\text { among the most frequent } \\
\text { adverse events }\end{array}$ & $>$ & $>$ & & & & & & \\
\hline $\begin{array}{l}\text { Systematic review of randomized } \\
\text { controlled trials of TCIs compared } \\
\text { with topical corticosteroids or vehicle } \\
\text { in patients of any age with AD } \\
(n=7,378)[19]\end{array}$ & & $>$ & $>$ & $=$ & & $>$ & $=$ & $<$ & \\
\hline $\begin{array}{l}\text { Meta-analysis of randomized controlled } \\
\text { trials of TCIs compared with topical } \\
\text { corticosteroids or vehicle in children } \\
\text { with AD }(n=4,234)[20]\end{array}$ & $\begin{array}{l}\text { Both TCIs have tolerability } \\
\text { profiles similar to vehicle }\end{array}$ & & $>$ & & & $>^{c}$ & $>^{d}$ & & \\
\hline $\begin{array}{l}\text { Meta-analysis of randomized controlled } \\
\text { trials of tacrolimus compared with } \\
\text { topical corticosteroids in children } \\
(n=2,328) \text { and adults }(n=2,849) \\
\text { with AD [21] }\end{array}$ & $\begin{array}{l}\text { Tacrolimus and topical } \\
\text { corticosteroids are similar in } \\
\text { tolerability, with the } \\
\text { exception of skin burning }\end{array}$ & & $>$ & $>$ & $=$ & & & & \\
\hline
\end{tabular}

$A D$ atopic dermatitis, $C S$ corticosteroid, $H C T$ hydrocortisone, $T C I$ topical calcineurin inhibitor

$>$ indicates more effective, $<$ indicates less effective, $=$ indicates as effective

${ }^{a}$ As identified using PubMed searches for peer-reviewed systematic reviews or meta-analyses comparing the efficacy and/or tolerability of tacrolimus and/or pimecrolimus with topical corticosteroids in patients with atopic eczema [ie, topical and (tacrolimus or pimecrolimus or calcineurin) and (corticosteroids or halobetasol or diflorasone or desoximetasone or clocortolone or triamcinolone or betamethasone or hydrocortisone or clobetasol or fluocinonide or fluocinolone or mometasone or fluticasone or alclometasone or prednicarbate or desonide) and (eczema or "atopic dermatitis"), limited to systematic review/meta-analysis publication type, human species, and English language]

b Comparisons not available or limited

c Applied to face, neck, and intertriginous areas

d Applied to trunk and limbs

\subsection{Criticism}

The FDA's decision prompted criticism by various experts [29-32] and medical associations, including the American College of Allergy Asthma and Immunology (ACAAI) and the American Academy of Allergy, Asthma, and Immunology (AAAAI) [33], and the American Academy of Dermatology (AAD) [34]. The critics asserted that the benefit-risk ratio had not been assessed appropriately, especially in light of the impact of $\mathrm{AD}$ on patients and the 
risk of significant adverse effects with topical corticosteroids [30-32]. They contended that the results of the animal studies, which were conducted with an aim of determining dosages that produced toxicity, could not be generalized to humans because of differences in administration and/or formulation, inherent biological differences between humans and animals, and large differences in systemic exposure (26- to 340 -fold greater than the maximum levels observed in humans) [29, 33].

In addition, they pointed out that the incidence of lymphoma in TCI-treated patients was no greater than that seen in the general population. In fact, in the pimecrolimus post-marketing surveillance (including solicited, spontaneous, and literature reports), the incidence of any lymphoma is $0.41 / 100,000$ patient-years of exposure [2], whereas the age-adjusted incidence of Hodgkin's and non-Hodgkin's lymphoma combined in the general population is 22.0/100,000 patient-years [35]. That is, there is up to approximately a 54-fold higher incidence of lymphoma in the general population compared with those exposed to topical pimecrolimus; however, such calculations based on post-marketing reports are subject to under-reporting. Even if only $5 \%$ of actual lymphoma cases are reported, the adjusted incidence of lymphoma among TCI users would still be nearly threefold lower than the background incidence in the general population. Furthermore, experts agree that misdiagnosis due to overlapping presentation with cutaneous $\mathrm{T}$ cell lymphoma (CTCL) and an association between AD itself and cancer risk complicate the analysis [36].

\section{New Evidence, Incomplete Conclusions}

A comprehensive review of TCI safety was released by the FDA in September 2010 [37], with an addendum released in May 2011 [38]. The 2010 review summarized data from five peer-reviewed studies [39-43] and a study that has so far been published only in abstract form [44, 45]; these six studies evaluated a combined population of $>6$ million patients [37] (Table 2).

Despite this large volume of epidemiological data, the FDA concluded that there still may be "a possibility of an association" between tacrolimus (pimecrolimus is not mentioned) and an increased risk of lymphoma but, "causality is difficult to determine in light of potential study biases" and "applicability of the reported results specifically to the pediatric population and the longterm safety profile of [tacrolimus] remain in question [38]".

As of May 2011, a total of 72 cases of malignancy in TCI-treated children had been reported to the FDA (17 before the Boxed Warning and 55 after): 25 lymphomas, 25 leukemias, 8 skin malignancies, and 14 other types of cancer [46]. The FDA reviewers concluded that these cases "support the previously observed potential signal for malignancies reported with TCI use"; however, they also state that the available information is not sufficient to determine causality.

\section{An Allergist's Perspective: Optimizing Therapy with TCIs}

\subsection{Recommendations}

As noted above, the total number of TCI prescriptions has fallen precipitously since 2004 [27]. This suggests that a relatively large number of patients have been denied the benefits of TCI therapy on the grounds of a speculative assessment of risk. Also implied is an increase in topical corticosteroid use, along with all its associated risks, especially when used in sensitive areas such as the face and around the eyes [12]. While care should be used in prescribing TCIs, available evidence suggests that the concerns of the PAC have not been borne out during the 7 years since the Boxed Warning was initiated. Although topical corticosteroids should remain first-line therapy for $\mathrm{AD}$ flares, there are a number of situations in which TCIs should be considered. Currently, TCIs are indicated for use in patients who do not respond to topical corticosteroid treatment or in whom topical corticosteroid use is contraindicated [22, 23]. In addition, for patients with particularly severe $\mathrm{AD}$ who require long-term treatment, chronic intermittent and proactive use of TCIs may be more appropriate than topical corticosteroids, given the limited data available for long-term use of topical corticosteroids [47]. Likewise, in sensitive skin areas such as the face, neck, or genitals, corticosteroid use may not be suitable due to a greater risk of telangiectasia and higher systemic exposure resulting from a thinner epidermal barrier in those areas [3, 4]. Furthermore, corticosteroid use in the periorbital region can lead to corticosteroid-induced vasoconstriction and glaucoma [4]. These concerns are particularly relevant in the case of children, who are more likely to have $\mathrm{AD}$, more likely to have $\mathrm{AD}$ in sensitive-skin areas, and have a higher body surface/volume ratio that enhances the risk of systemic exposure to corticosteroids. In rare cases, systemic exposure may lead to hypothalamic-pituitaryadrenal axis suppression and growth retardation [4]. In some instances, it may also be reasonable to consider using TCIs in combination with topical corticosteroids; for example, the use of a topical corticosteroid of appropriate potency on the body (i.e., below the neck) and a TCI on the face, or in areas where topical corticosteroids have been ineffective. With such an approach, the total exposure to both TCIs and topical corticosteroids would be reduced, thereby decreasing the risk 
Table 2 Epidemiological studies of topical calcineurin inhibitor use and malignancy risk (including lymphoma) ${ }^{\mathrm{a}}$

\begin{tabular}{|c|c|c|}
\hline Database & Design and population & Results \\
\hline $\begin{array}{l}\text { Survey of dermatology } \\
\text { outpatients with AD }\end{array}$ & $\begin{array}{l}\text { Nested case-controlled cohort of } 3,535 \\
\text { patients }>30 \text { years of age }\end{array}$ & $\begin{array}{l}\text { - No association between TCI use and increased risk of non- } \\
\text { melanoma skin cancer [39] }\end{array}$ \\
\hline $\begin{array}{l}\text { US PharMetrics Health Claims } \\
\text { Database }\end{array}$ & $\begin{array}{l}\text { Nested case-controlled cohort of } 293,253 \\
\text { patients of any age with AD }\end{array}$ & $\begin{array}{l}\text { - No increased risk of lymphoma in TCI-treated patients } \\
\text { compared with non-use [40] } \\
\text { - Severity of AD was the main factor associated with } \\
\text { increased risk of lymphoma [40] } \\
\text { - } 9 \text { of } 81 \text { patients }<20 \text { years of age who developed } \\
\text { lymphoma had TCI exposure-4 to tacrolimus, } 4 \text { to } \\
\text { pimecrolimus, and } 1 \text { to both [38] }\end{array}$ \\
\hline $\begin{array}{l}\text { US PharMetrics Health Claims } \\
\text { Database (extension of } \\
\text { previous) }\end{array}$ & $\begin{array}{l}\text { Nested case-controlled cohort of } 625,915 \\
\text { patients of any age with AD }\end{array}$ & $\begin{array}{l}\text { - No increased risk of overall lymphoma in TCI- or topical } \\
\text { corticosteroid-treated patients compared with non-use; } \\
\text { results were similar for patients }<20 \text { years of age }[38,44 \text {, } \\
45] \\
\text { - Possible significantly higher risk of non-Hodgkin's and } \\
\text { T-cell lymphoma in patients treated with tacrolimus (but } \\
\text { not pimecrolimus) compared with non-use }[38,45]\end{array}$ \\
\hline
\end{tabular}

\begin{tabular}{cc}
\hline The Health Improvement & Nested case-control study of 3,500,194 \\
Network (THIN) Electronic & patients $<80$ years of age who used TCIs or \\
Medical Record Database & topical corticosteroids
\end{tabular}

- No association between TCI use and lymphoma risk ${ }^{\mathrm{b}}$ [41]

Medical Record Database topical corticosteroids

- Significant correlation between topical corticosteroid use and risk of lymphoma, especially skin lymphoma [41]

Kaiser Permanente California Databases
Cohort of 953,064 patients of any age with $\mathrm{AD}$

- No association between TCI use and risk of malignancy [42]

- Possible association between risk of CTCL and exposure to tacrolimus (but not pimecrolimus) [42]

- 1 of 12 patients with a confirmed diagnosis of lymphoma was $\leq 20$ years of age (this patient was exposed to both TCIs) [38]

United Health Care Health Claims Database

\author{
Propensity-matched cohort of 1,200,645 \\ patients of any age including: \\ - Patients with AD who initiated \\ pimecrolimus, tacrolimus, or medium/ \\ potent topical corticosteroids \\ - Patients with AD who did not initiate AD \\ treatment \\ - Controls without AD who had no TCI/ \\ topical corticosteroid exposure
}
- No increased risk of lymphoma (including CTCL) with initiation of pimecrolimus compared with initiation of tacrolimus or medium/potent topical corticosteroids [43]
- Of patients $\leq 5$ years of age:
None had a diagnosis of lymphoma during the 6-month period following the index date [38]
Two had a diagnosis of lymphoma overall (one patient with CTCL and one with "any lymphoma"; both were exposed to tacrolimus) [38]

$A D$ atopic dermatitis, $C T C L$ cutaneous T-cell lymphoma, $T C I$ topical calcineurin inhibitor

a As identified in the FDA's calcineurin inhibitor pediatric literature review [37, 38]

b The low number of TCI-treated patients made the determination of a link impossible

of adverse effects associated with either drug class. Furthermore, counselling patients to limit or avoid sun exposure will mitigate risk of cutaneous malignancy, as recommended in the package insert [23].

\subsection{Challenges Associated with Prescribing TCIs}

Due to the Boxed Warning, prescribing TCIs has become difficult due to a number of factors, not least of which is barriers to patient access and reimbursement put in place by insurers and other payers. Even when they are prescribed as indicated, the Boxed Warning often dissuades patients, and even some doctors (especially those less familiar with the history of the debate), from using them. However, it is our responsibility, as physicians, to ensure that patients receive the best possible care, particularly when first-line therapies do not provide sufficient relief, or if there are relevant safety concerns. We physicians must also sufficiently explain the benefits and risks of the therapies we prescribe, which, in the case of TCIs, may require longer consultation times. There is currently no standard method for communicating the risks and benefits of TCIs. A consensus document, directed toward 
patients and caregivers, that places the risks into context would be useful. Unfortunately, no such document exists. Until such a document becomes available, physicians should stay informed of the issues surrounding TCI use so that they can adequately answer questions and discuss potential problems with insurance coverage and/or preauthorization prior to prescribing. It is also important to work with pharmacists to consistently communicate the risks and benefits of pharmacotherapies for AD.

Due to the relatively low incidence of malignancy (including lymphoma) in patients taking TCIs, it may never be possible to completely exclude the possibility of a causal relationship between TCI use and cancer, regardless of the number of patients who are monitored. However, some patients and caregivers may be comforted by the fact that both $\mathrm{AAD}$ and AAAAI/ACAAI have challenged the inclusion of the Boxed Warning. The AAD website states that:

\section{The medicines that dermatologists prescribe are safe when used as directed...The [AAD] believes that these Warnings confuse and unnecessarily worry people. Studies prove that with proper use, topical pimecrolimus and tacrolimus are not dangerous. When applied to the skin, virtually none of the med- icine gets inside the body. When used properly, the medicines reduce the debilitating effect of [AD] and allow millions of people to live normal lives [48].}

\section{Conclusions}

In the 7 years since the Boxed Warning was implemented, no conclusive proof has emerged that links TCI use to malignancy risk, despite extensive monitoring and analysis. However, a theoretical possibility remains, and so does the Boxed Warning. In this context, it may be appropriate to challenge the treatment paradigm of using TCIs only after failure of topical corticosteroids. Not adopting such a treatment strategy may deprive many patients, especially children, of effective AD management, while putting them at risk for corticosteroid-associated adverse effects. That is why the author recommends (and currently prescribes, when appropriate) TCIs for sensitive skin areas ("above the neck") and topical corticosteroids for the rest of the body ("below the neck"). In the meantime, we as physicians must remain informed about this debate and be ready to explain the benefit-risk ratios of both TCIs and topical corticosteroids to our patients and their caregivers. Continued monitoring and future studies may shed more light on this question.

Acknowledgments Dr. Carr played a key role in the development of this manuscript. Vojislav Pejović and Michael Miller of Prescott
Medical Communications Group (Chicago, IL, USA) provided medical writing and editorial support with funding support from Valeant Pharmaceuticals North America LLC (Bridgewater, NJ, USA). All content was developed independently of the funding source. Dr. Carr has received consulting fees and/or served on advisory boards for Alcon Laboratories (a division of the Novartis Group), AstraZeneca, Meda AB, Sanofi, Sunovion Pharmaceuticals Inc. (formerly Sepracor Inc.), and Teva Pharmaceutical Industries Ltd. In addition, he has been a member of speakers' bureaus for Alcon Laboratories, AstraZeneca, Meda AB, Teva Pharmaceutical Industries Ltd, and GlaxoSmithKline. $\mathrm{He}$ has also participated in contract research with Alcon Laboratories, Novartis Pharmaceuticals Corporation, AstraZeneca, Meda AB, Sunovion Pharmaceuticals Inc., Teva Pharmaceutical Industries Ltd, GlaxoSmithKline, ISTA Pharmaceuticals Inc. (now Bausch \& Lomb), and Genentech, Inc. (a member of the Roche Group).

Open Access This article is distributed under the terms of the Creative Commons Attribution Noncommercial License which permits any noncommercial use, distribution, and reproduction in any medium, provided the original author(s) and the source are credited.

\section{References}

1. Williams HC. Clinical practice. Atopic dermatitis. N Engl J Med. 2005;352(22):2314-24.

2. Valeant Pharmaceuticals North America. Data on file, 2012.

3. Draelos ZD. Use of topical corticosteroids and topical calcineurin inhibitors for the treatment of atopic dermatitis in thin and sensitive skin areas. Curr Med Res Opin. 2008;24(4):985-94.

4. Hengge UR, Ruzicka T, Schwartz RA, et al. Adverse effects of topical glucocorticosteroids. J Am Acad Dermatol. 2006;54(1):1-15. (quiz 16-18).

5. Williams HC, Burney PG, Pembroke AC, et al. The UK working party's diagnostic criteria for atopic dermatitis. III. Independent hospital validation. Br J Dermatol. 1994;131(3):406-16.

6. Odhiambo JA, Williams HC, Clayton TO, et al. Global variations in prevalence of eczema symptoms in children from ISAAC Phase Three. J Allergy Clin Immunol. 2009;124(6):1251-1258.e1223.

7. Shaw TE, Currie GP, Koudelka CW, et al. Eczema prevalence in the United States: data from the 2003 National Survey of Children's Health. J Invest Dermatol. 2011;131(1):67-73.

8. Leung DY, Bieber T. Atopic dermatitis. Lancet. 2003;361(9352): 151-60.

9. Bieber T. Atopic dermatitis. Ann Dermatol. 2010;22(2):125-37.

10. Protopic ${ }^{\circledR}$ (Tacrolimus) ointment $0.03 \%$ and ointment $0.1 \%$ (US prescribing information). Deerfield (IL): Fujisawa Healthcare, Inc.; 2000.

11. Elidel $^{\circledR}$ (Pimecrolimus) cream $1 \%$ (US prescribing information). East Hanover (NJ): Novartis Pharmaceuticals Corporation.; 2001.

12. Horii KA, Simon SD, Liu DY, et al. Atopic dermatitis in children in the United States, 1997-2004: visit trends, patient and provider characteristics, and prescribing patterns. Pediatrics. 2007;120(3): e527-34.

13. Stuetz A, Baumann K, Grassberger M, et al. Discovery of topical calcineurin inhibitors and pharmacological profile of pimecrolimus. Int Arch Allergy Immunol. 2006;141(3):199-212.

14. Lin AN. Innovative use of topical calcineurin inhibitors. Dermatol Clin. 2010;28(3):535-45.

15. Prograf ${ }^{\circledR}$ (tacrolimus) capsules and injection (US prescribing information). Deerfield (IL): Astellas Pharma US, Inc.; 2011.

16. Iskedjian $\mathrm{M}$, Piwko $\mathrm{C}$, Shear $\mathrm{NH}$, et al. Topical calcineurin inhibitors in the treatment of atopic dermatitis: a meta-analysis of current evidence. Am J Clin Dermatol. 2004;5(4):267-79. 
17. Ashcroft DM, Dimmock P, Garside R, et al. Efficacy and tolerability of topical pimecrolimus and tacrolimus in the treatment of atopic dermatitis: meta-analysis of randomised controlled trials. BMJ. 2005;330(7490):516.

18. Yan J, Chen SL, Wang XL, et al. Meta-analysis of tacrolimus ointment for atopic dermatitis in pediatric patients. Pediatr Dermatol. 2008;25(1):117-20.

19. El-Batawy MM, Bosseila MA, Mashaly HM, et al. Topical calcineurin inhibitors in atopic dermatitis: a systematic review and meta-analysis. J Dermatol Sci. 2009;54(2):76-87.

20. Chen SL, Yan J, Wang FS. Two topical calcineurin inhibitors for the treatment of atopic dermatitis in pediatric patients: a metaanalysis of randomized clinical trials. J Dermatolog Treat. 2010; 21(3):144-56.

21. Svensson A, Chambers C, Ganemo A, et al. A systematic review of tacrolimus ointment compared with corticosteroids in the treatment of atopic dermatitis. Curr Med Res Opin. 2011;27(7):1395-406.

22. Protopic ${ }^{\circledR}$ (Tacrolimus) ointment $0.03 \%$ and ointment $0.1 \%$ (US prescribing information). Deerfield (IL): Astellas Pharma US, Inc.; 2011.

23. Elidel ${ }^{\circledR}$ (Pimecrolimus) cream $1 \%$ (US prescribing information). East Hanover (NJ): Novartis Pharmaceuticals Corporation.; 2010.

24. Pediatric Advisory Committee presentation from Barbara Hill, Division of Dermatologic and Dental Drug Products, FDA Center for Drug Evaluation and Research. Topical immunosuppressants (calcineurin inhibitors)—animal toxicology, 15 Feb 2005. Available from URL: http://www.fda.gov/ohrms/dockets/ac/05/ slides/2005-4089s2_01_06_Hill.ppt. Accessed 2 Apr 2012.

25. US Department of Health and Human Services, Food and Drug Administration, Center for Drug Evaluation and Research (CDER). Protopic NDA 50-777 approval letter, 8 Dec 2000. Available from URL: http://www.accessdata.fda.gov/drugsatfda docs/nda/2000/50777_Protopic_Approv.pdf. Accessed 23 Jan 2012.

26. US Department of Health and Human Services, Food and Drug Administration, Center for Drug Evaluation and Research (CDER). Elidel NDA 21-302 approval letter, 13 Dec 2001. Available from URL: http://www.accessdata.fda.gov/drugsatfda docs/nda/2001/21-302_ELIDEL_Approv.pdf. Accessed 23 Jan 2012.

27. Briefing document from Patty Greene, Drug Use Data Analyst, Division of Epidemiology, Office of Surveillance and Epidemiology, FDA Center for Drug Evaluation and Research. BPCA drug use review: Comparison of Elidel ${ }^{\circledR}$ cream and Protopic ${ }^{\circledR}$ ointment utilization trends following 2006 labeling changes, 17 July 2009. Available from URL: http://www.fda.gov/downloads/ AdvisoryCommittees/CommitteesMeetingMaterials/PediatricAd visoryCommittee/UCM204723.pdf. Accessed 2 Apr 2012.

28. Minutes of the Pediatric Advisory Committee meeting. $15 \mathrm{Feb}$ 2005. Available from URL: http://www.fda.gov/ohrms/dockets/ ac/05/minutes/2005-4089m1_Minutes.pdf. Accessed 4 Apr 2012.

29. Ring J, Mohrenschlager M, Henkel V. The US FDA 'black box' warning for topical calcineurin inhibitors: an ongoing controversy. Drug Saf. 2008;31(3):185-98.

30. Spergel JM, Leung DY. Safety of topical calcineurin inhibitors in atopic dermatitis: evaluation of the evidence. Curr Allergy Asthma Rep. 2006;6(4):270-4.

31. Fleischer AB Jr. Black box warning for topical calcineurin inhibitors and the death of common sense. Dermatol Online J. 2006;12(6):2.

32. Lebwohl M, Gower T. A safety assessment of topical calcineurin inhibitors in the treatment of atopic dermatitis. MedGenMed. 2006;8(4):8

33. Fonacier L, Spergel J, Charlesworth EN, et al. Report of the topical calcineurin inhibitor task force of the American College of Allergy, Asthma and Immunology and the American Academy of Allergy, Asthma and Immunology. J Allergy Clin Immunol. 2005;115(6):1249-53.
34. American Academy of Dermatology issues statement in response to FDA decision related to two eczema medications (news release). American Academy of Dermatology (AAD); 20 Mar 2005. Available from URL: http://www.thefreelibrary.com/ American+Academy + of +Dermatology + Issues + Statement + In + Response+to+FDA...-a0130070456. Accessed 5 Apr 2012.

35. Fast Stats: an interactive tool for access to SEER cancer statistics. Surveillance Research Program, National Cancer Institute. http://seer.cancer.gov/faststats. Accessed 8 June 2012.

36. Tennis P, Gelfand JM, Rothman KJ. Evaluation of cancer risk related to atopic dermatitis and use of topical calcineurin inhibitors. Br J Dermatol. 2011;165(3):465-73.

37. Briefing document from Angelika Manthripragada, Epidemiologist, Division of Epidemiology, Office of Surveillance and Epidemiology, FDA Center for Drug Evaluation and Research. Calcineurin inhibitor pediatric literature review, 23 Sept 2010. Available from URL: http://www.fda.gov/downloads/Advisory Committees/CommitteesMeetingMaterials/PediatricAdvisoryCo mmittee/UCM255139.pdf. Accessed 23 Jan 2012.

38. Briefing document from Angelika Manthripragada, Epidemiologist, Division of Epidemiology, Office of Surveillance and Epidemiology, FDA Center for Drug Evaluation and Research. Addendum: update on calcineurin inhibitor pediatric literature review, 10 May 2011. Available from URL: http://www.fda.gov/ downloads/AdvisoryCommittees/CommitteesMeetingMaterials/ PediatricAdvisoryCommittee/UCM255140.pdf. Accessed 23 Jan 2012.

39. Margolis DJ, Hoffstad O, Bilker W. Lack of association between exposure to topical calcineurin inhibitors and skin cancer in adults. Dermatology. 2007;214(4):289-95.

40. Arellano FM, Wentworth CE, Arana A, et al. Risk of lymphoma following exposure to calcineurin inhibitors and topical steroids in patients with atopic dermatitis. J Invest Dermatol. 2007; 127(4):808-16.

41. Arellano FM, Arana A, Wentworth CE, et al. Lymphoma among patients with atopic dermatitis and/or treated with topical immunosuppressants in the United Kingdom. J Allergy Clin Immunol. 2009;123(5):1111-6.e1113.

42. Hui RL, Lide W, Chan J, et al. Association between exposure to topical tacrolimus or pimecrolimus and cancers. Ann Pharmacother. 2009;43(12):1956-63.

43. Schneeweiss S, Doherty M, Zhu S, et al. Topical treatments with pimecrolimus, tacrolimus and medium- to high-potency corticosteroids, and risk of lymphoma. Dermatology. 2009;219(1):7-21.

44. Arana A, Wentworth CW, Rivero E, et al. Lymphoma among patients with atopic dermatitis treated with topical corticosteroids and/or topical calcineurin inhibitors (abstract). J Am Acad Dermatol. 2011;64(2 Suppl 1):AB3. (Abstract P203).

45. Arana A, Wentworth CW, Rivero E, et al. Lymphoma among patients with atopic dermatitis treated with topical corticosteroids (TCS) and/or topical calcineurin inhibitors (TCIs) (abstract). Pharmacoepidemiol Drug Saf. 2010;19:S12. (Abstract 28).

46. Briefing document from Namita Kothary, Safety Evaluator, Division of Pharmacovigilance I, Office of Surveillance and Epidemiology, FDA Center for Drug Evaluation and Research. Update on Malignancies in Children, 4 Apr 2011. Available from URL: http://www.fda.gov/downloads/AdvisoryCommittees/Com mitteesMeetingMaterials/PediatricAdvisoryCommittee/UCM255 145.pdf. Accessed 23 Jan 2012.

47. National Eczema Association (NEA). Topical corticosteroids: myths and facts. http://www.nationaleczema.org/eczema-treat ments/topical-corticosteroids. Accessed 2 Apr 2012.

48. American Academy of Dermatology (AAD). Atopic dermatitis: tips for managing. http://www.aad.org/skin-conditions/dermatologya-to-z/atopic-dermatitis/tips/atopic-dermatitis-tips-for-managing . Accessed 20 Apr 2012. 